\title{
Often Overlooked and Ignored, but Do Not Underestimate Its Relevance: ADHD in Addiction - Addiction in ADHD
}

\author{
Arnt F.A. Schellekens ${ }^{a, b}$ Wim van den Brink ${ }^{c} \quad$ Falk Kiefer $^{\text {d, e }}$ \\ Anneke E. Goudriaan ${ }^{f, g}$ \\ aProfessor of Psychiatry and Addiction, Department of Psychiatry, RadboudUmc, Donders Institute for Brain,

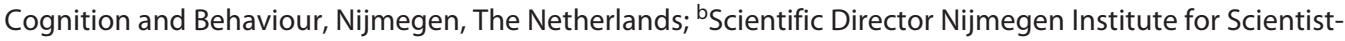 \\ Practitioners in Addiction (NISPA), Nijmegen, The Netherlands; ' ${ }^{C}$ meritus Professor of Psychiatry and Addiction, \\ Department of Psychiatry, Amsterdam University Medical Centers, Location Academic Medical Center, Amsterdam, \\ The Netherlands; PProfessor of Psychiatry and Psychotherapy, University of Heidelberg, Mannheim, Germany; \\ eDirector of Department of Addictive Behavior and Addiction Medicine, Central Institute of Mental Health, Medical \\ Faculty Mannheim/Heidelberg University, Mannheim, Germany; ${ }^{\text {fP }}$ rofessor of Working Mechanisms and Treatment \\ of Addiction, Department of Psychiatry, Amsterdam University Medical Centers, Location Academic Medical Center, \\ Amsterdam, The Netherlands; ${ }^{9}$ Director Amsterdam Institute for Addiction Research, Amsterdam, The Netherlands
}

This special issue of European Addiction Research (EAR) ratifies that there is an urgent need to foreground the initially ignored and then underestimated topic of an addiction-ADHD comorbidity, and to acknowledge the 10th anniversary of the International Collaboration on ADHD and Substance Abuse (ICASA: https://www. adhdandsubstanceabuse.org) that has dedicated itself to that unmet need.

ADHD and substance use disorders (SUDs) are both common mental disorders that commonly co-occur [1]. In the general population, $\mathrm{ADHD}$ occurs in about $6 \%$ of children and adolescents and about $2.5 \%$ of adults $[2,3]$. Combining 27 general population and clinical studies with more than 4,000 ADHD participants and almost 7,000 non-ADHD participants, those with ADHD were about 2-3 times more likely to develop a nicotine, alcohol, marijuana, cocaine, and/or other substance use disorders than those without ADHD [4]. In adult SUD pa-

karger@karger.com www.karger.com/ear Karger" BOPEN ACCESS
(C) 2020 The Author(s)

Published by S. Karger AG, Basel

This is an Open Access article licensed under the Creative Commons Attribution-NonCommercial-4.0 International License (CC BY-NC) (http://www.karger.com/Services/OpenAccessLicense), applicable to the online version of the article only. Usage and distribution for commercial purposes requires written permission. tients, the prevalence of ADHD is estimated at around $20 \%$ [5-7]. Furthermore, SUD patients with comorbid ADHD have an earlier onset of substance use, a faster transition to SUD, and a higher risk of relapse compared to those without ADHD [8-11].

Given the high prevalence and impact of co-occurring ADHD in patients with SUD, this is an important clinical challenge that calls for scientific evidence supporting clinical decision making. To this end, ICASA was founded 10 years ago. Over the past decade, ICASA and others have built a great deal of evidence concerning SUD-ADHD comorbidity. Where ADHD is still often overlooked or ignored in SUD patients, these scientific insights indicate that in patients with SUD, ADHD should be considered a valid and highly relevant psychiatric diagnosis. It is a chronic neurodevelopmental condition, where symptoms of inattention and/or hyperactivity/impulsivity lead to additional impairments in many aspects of living. 
Given the high prevalence and impact of ADHD in patients with SUD, screening for ADHD should be part of standard intake procedures in addiction care. Moreover, ADHD can be reliably assessed in patients with SUD even when they are not (yet) fully abstinent [12]. There are several reliable screening and diagnostic tools available for this purpose, as summarized in the ICASA consensus statement on the screening, diagnosis, and treatment of adult SUD patients with comorbid ADHD [13]. In addition, several studies suggest that early stimulant treatment of childhood ADHD can prevent the development of SUD $[10,14-21]$ and that pharmacotherapy of ADHD can improve outcomes in SUD patients with comorbid ADHD [13, 22]. It should be noted, however, that studies have also shown that the neural response to stimulant treatment in ADHD patients with SUD may differ from the response in ADHD patients without SUD [23] and that - as a consequence - higher doses may be needed in at least some of the patients with ADHD and SUD $[24,25]$. These insights are highly relevant for clinical practice and should find their way to (inter)national guidelines.

In addition, there are new insights in the biological underpinnings of the frequent co-occurrence of SUD and ADHD. ADHD and SUD belong to the more heritable psychiatric conditions [26-31], and both twin and genome-wide association studies have indicated a strong shared heritability of ADHD and SUD [32, 33]. These findings suggest that the frequent co-occurrence of these conditions has a shared biological background. Similarly, neurocognitive and neuroimaging studies have identified cognitive control pathways, reward pathways, and emotion regulation pathways to be centrally involved in both conditions [34, 35]. Though these insights further our understanding of this frequent comorbidity, there is still much to learn about the exact causal mechanisms contributing to SUD-ADHD comorbidity.

The 10-year anniversary of ICASA marks a decade of intense and fruitful international collaboration. With this special issue of EAR, we share some of the most recent developments in this field of research with special attention to some new findings from the ICASA network. This special issue contains 6 papers on recently collected data by the ICASA network showing increased severity of SUD and increased severity of smoking in SUD patients with comorbid ADHD compared to those without ADHD (Icick et al., 2020; Sanchez-Garcia et al., 2020 , respectively); prevalence data on ADHD in prisoners with SUD (Velez-Patrana et al., 2020); new data on the role of antisocial traits in the development of comor- bidity between ADHD and SUD (Gonzalez et al., 2020); a review on the role of sustained attention in the diagnosis of patients with SUD-ADHD comorbidity (Slobodin, 2020); and finally a consensus paper concerning the clinical assessment and treatment of adolescents with SUD and ADHD (Özgen et al., 2020). Here we like to emphasize that the ICASA consensus papers (Ozgen et al., 2020; [13]), although important and clinically needed, are no substitution for evidence-based guidelines.

Additionally, several papers are included in this issue focusing on frequent other comorbidities in patients with SUD and ADHD, including PTSD (Luderer et al., 2020), personality traits (Moggi et al., 2020), polysubstance use in SUD patients with and without ADHD (Lugoboni et al., 2020), and the effect of alcohol use and a family history of alcohol dependence on reward-delay aversion in adolescents with ADHD with and without SUDs (Paraskevopoulou et al., 2020).

Based on data presented in this special issue of EAR, we conclude that this field has shown great advancement over the past years, but also that a lot of work has yet to be done. For instance, future studies should address the question concerning personalized treatment of patients with both conditions. For instance, what is the best pharmacological treatment of patients with SUD and ADHD (e.g., stimulants or atomoxetine) and how can robust doses of stimulants be prescribed without the risk of serious side-effects (insomnia, cardiovascular problems, and diversion)? Furthermore, there is a remarkable paucity of data on (integrated) psychological treatment of SUD with comorbid ADHD and the outcome predictors of such interventions $[36,37]$. There is an urgent need for evidence concerning which psychological treatments work best for patients suffering both conditions, and how SUD treatment should be adapted when patients have comorbid ADHD, and vice versa. Another major issue in the existing literature is the lack of prospective data on real-life clinical experiences in the treatment of SUD patients with comorbid ADHD. The INCAS study, as presented in this issue (Brynte et al., 2020), will shed light on the course of these disorders when these patients enter addiction care, and provide insight into outcome of different treatment approaches across the participating countries.

Taken together, the SUD-ADHD field is rapidly developing. After 10 years of work, the ICASA group is alive and kicking. New members have been welcomed over the recent years, and several young scientists have joined, dedicating their work to this relevant topic. ICASA strives to foster its work in prevention and clinical 
care for patients with SUD and comorbid ADHD through scientific evidence. We wish all readers an inspiring experience when reading this Special Issue.

\section{Disclosure Statement}

None of the authors have a conflict of interest to declare.

\section{References}

1 Wilens TE, Morrison NR. The intersection of attention-deficit/hyperactivity disorder and substance abuse. Curr Opin Psychiatry. 2011; 24(4):280-5.

2 Simon V, Czobor P, Bálint S, Mészáros A, Bitter I. Prevalence and correlates of adult attention-deficit hyperactivity disorder: metaanalysis. Br J Psychiatry. 2009;194(3):204-11.

3 Willcutt EG. The prevalence of DSM-IV attention-deficit/hyperactivity disorder: a meta-analytic review. Neurotherapeutics. 2012; 9(3):490-9.

4 Lee SS, Humphreys KL, Flory K, Liu R, Glass K. Prospective association of childhood attention-deficit/hyperactivity disorder (ADHD) and substance use and abuse/dependence: a meta-analytic review. Clin Psychol Rev. 2011; 31(3):328-41.

5 van Emmerik-van Oortmerssen $\mathrm{K}$, van de Glind G, Koeter MW, Allsop S, Auriacombe $\mathrm{M}$, Barta C, et al. Psychiatric comorbidity in treatment-seeking substance use disorder patients with and without attention deficit hyperactivity disorder: results of the IASP study. Addiction. 2014;109(2):262-72.

6 van de Glind G, Konstenius M, Koeter MWJ, van Emmerik-van Oortmerssen K, Carpentier PJ, Kaye S, et al. Variability in the prevalence of adult ADHD in treatment seeking substance use disorder patients: results from an international multi-center study exploring DSM-IV and DSM-5 criteria. Drug Alcohol Depend. 2014;134:158-66.

7 Groenman AP, Oosterlaan J, Rommelse N, Franke B, Roeyers H, Oades RD, et al. Substance use disorders in adolescents with attention deficit hyperactivity disorder: a 4-year follow-up study. Addiction. 2013;108(8): 1503-11.

8 Hahesy AL, Wilens TE, Biederman J, Van Patten SL, Spencer T. Temporal association between childhood psychopathology and substance use disorders: findings from a sample of adults with opioid or alcohol dependency. Psychiatry Res. 2002;109(3):245-53.

9 McCabe SE, Dickinson K, West BT, Wilens TE. Age of onset, duration, and type of medication therapy for attention-deficit/hyperactivity disorder and substance use during adolescence: a multi-cohort national study. J Am Acad Child Adolesc Psychiatry. 2016;55(6): 479-86.

10 Wilens TE. Impact of ADHD and its treatment on substance abuse in adults. J Clin Psychiatry. 2004;65(Suppl 3):38-45.
11 Castells X, Ramos-Quiroga JA, Rigau D, Bosch R, Nogueira M, Vidal X, et al. Efficacy of methylphenidate for adults with attentiondeficit hyperactivity disorder: a meta-regression analysis. CNS Drugs. 2011;25(2):157-69.

12 van Emmerik-van Oortmerssen K, Vedel E, Kramer FJ, Koeter MW, Schoevers RA, van den Brink W. Diagnosing ADHD during active substance use: feasible or flawed? Drug Alcohol Depend. 2017;180:371-5.

13 Crunelle CL, van den Brink W, Moggi F, Konstenius M, Franck J, Levin FR, et al. International consensus statement on screening, diagnosis and treatment of substance use disorder patients with comorbid attention deficit/ hyperactivity disorder. Eur Addict Res. 2018; 24(1):43-51.

14 Biederman J, Monuteaux MC, Spencer T, Wilens TE, Macpherson HA, Faraone SV. Stimulant therapy and risk for subsequent substance use disorders in male adults with ADHD: a naturalistic controlled 10-year follow-up study. Am J Psychiatry. 2008;165(5): 597-603.

15 Faraone SV, Wilens T. Does stimulant treatment lead to substance use disorders? J Clin Psychiatry. 2003;64(Suppl 11):9-13.

16 Faraone SV, Biederman J, Wilens TE, Adamson J. A naturalistic study of the effects of pharmacotherapy on substance use disorders among ADHD adults. Psychol Med. 2007; 37(12):1743-52.

17 Faraone SV, Wilens TE. Effect of stimulant medications for attention-deficit/hyperactivity disorder on later substance use and the potential for stimulant misuse, abuse, and diversion. J Clin Psychiatry. 2007;68(Suppl 11): $15-22$.

18 Groenman AP, Oosterlaan J, Rommelse NN, Franke B, Greven CU, Hoekstra PJ, et al. Stimulant treatment for attention-deficit hyperactivity disorder and risk of developing substance use disorder. Br J Psychiatry. 2013; 203(2):112-9.

19 Groenman AP, Schweren LJS, Weeda W, Luman M, Noordermeer SDS, Heslenfeld DJ, et al. Stimulant treatment profiles predicting cooccurring substance use disorders in individuals with attention-deficit/hyperactivity disorder. Eur Child Adolesc Psychiatry. 2019; 28(9):1213-22.

20 Wilens TE, Faraone SV, Biederman J, Gunawardene S. Does stimulant therapy of attention-deficit/hyperactivity disorder beget later substance abuse? A meta-analytic review of the literature. Pediatrics. 2003;111(1):17985.
21 Wilens TE, Adamson J, Monuteaux MC, Faraone SV, Schillinger M, Westerberg $\mathrm{D}$, et al. Effect of prior stimulant treatment for attention-deficit/hyperactivity disorder on subsequent risk for cigarette smoking and alcohol and drug use disorders in adolescents. Arch Pediatr Adolesc Med. 2008;162(10):916-21.

22 Boland H, DiSalvo M, Fried R, Woodworth KY, Wilens T, Faraone SV, et al. A literature review and meta-analysis on the effects of ADHD medications on functional outcomes. J Psychiatr Res. 2020;123:21-30.

23 Crunelle CL, van den Brink W, Veltman DJ, van Emmerik-van Oortmerssen K, Dom G, Schoevers RA, et al. Low dopamine transporter occupancy by methylphenidate as a possible reason for reduced treatment effectiveness in ADHD patients with cocaine dependence. Eur Neuropsychopharmacol. 2013;23(12): 1714-23.

24 Konstenius M, Jayaram-Lindström N, Guterstam J, Beck O, Philips B, Franck J. Methylphenidate for attention deficit hyperactivity disorder and drug relapse in criminal offenders with substance dependence: a 24-week randomized placebo-controlled trial. Addiction. 2014;109(3):440-9.

25 Levin FR, Mariani JJ, Specker S, Mooney M, Mahony A, Brooks DJ, et al. Extended-release mixed amphetamine salts vs placebo for comorbid adult attention-deficit/hyperactivity disorder and cocaine use disorder: a randomized clinical trial. JAMA Psychiatry. 2015; 72(6):593-602.

26 Bidwell LC, Gray JC, Weafer J, Palmer AA, de Wit $\mathrm{H}$, MacKillop J. Genetic influences on ADHD symptom dimensions: examination of a priori candidates, gene-based tests, genome-wide variation, and SNP heritability. Am J Med Genet B Neuropsychiatr Genet. 2017;174(4):458-66.

27 Clarke TK, Adams MJ, Davies G, Howard DM, Hall LS, Padmanabhan S, et al. Genomewide association study of alcohol consumption and genetic overlap with other healthrelated traits in UK Biobank $(\mathrm{N}=112,117)$. Mol Psychiatry. 2017;22(10):1376-84.

28 Demers $\mathrm{CH}$, Bogdan R, Agrawal A. The genetics, neurogenetics and pharmacogenetics of addiction. Curr Behav Neurosci Rep. 2014; 1(1):33-44.

29 Faraone SV, Larsson H. Genetics of attention deficit hyperactivity disorder. Mol Psychiatry. 2019;24(4):562-75. 
30 Gorwood P, Le Strat Y, Ramoz N. Genetics of addictive behavior: the example of nicotine dependence. Dialogues Clin Neurosci. 2017; 19(3):237-45.

31 Wang JC, Kapoor M, Goate AM. The genetics of substance dependence. Annu Rev Genomics Hum Genet. 2012;13:241-61.

32 Vink J, Schellekens A. Relating addiction and psychiatric disorders. Science. 2018;361(6409): 1323-4.

33 Derks EM, Vink JM, Willemsen G, van den Brink W, Boomsma DI. Genetic and environmental influences on the relationship between adult ADHD symptoms and self-reported problem drinking in 6024 Dutch twins. Psychol Med. 2014;44(12):2673-83.
34 Luijten M, Schellekens AF, Kuehn S, Machielse MWJ, Sescousse G. Disruption of reward processing in addiction an imagebased meta-analysis of functional magnetic resonance imaging studies. Jama Psychiatry. 2017;74(4):387-98.

35 Plichta MM, Scheres A. Ventral-striatal responsiveness during reward anticipation in ADHD and its relation to trait impulsivity in the healthy population: a meta-analytic review of the fMRI literature. Neurosci Biobehav Rev. 2014;38:125-34.
36 van Emmerik-van Oortmerssen K, Vedel E, Kramer FJ, Blankers M, Dekker JJM, van den Brink W, et al. Integrated cognitive behavioral therapy for ADHD in adult substance use disorder patients: results of a randomized clinical trial. Drug Alcohol Depend. 2019;197: 28-3

37 van Emmerik-van Oortmerssen K, Blankers M, Vedel E, Kramer F, Goudriaan AE, van den Brink W, et al. Prediction of drop-out and outcome in integrated cognitive behavioral therapy for ADHD and SUD: results from a randomized clinical trial. Addict Behav. 2020; 103:106228. 